\title{
Relation of Renin Status to Neurogenic Vascular Resistance in Borderline Hypertension
}

MURRAY D. ESLER, MBBS, PhD

STEVO JULIUS, MD, ScD, FACC

OTELIO S. RANDALL, MD

CHARLES N. ELLIS

TOMOYOSHI KASHIMA, MD

Ann Arbor, Michigan
From the Hypertension Section, Department of Internal Medicine, University of Michigan Medical Center, Ann Arbor, Mich. This work was supported by the Michigan Heart Association (Dr. Julius) and U. S. Public Health Service Grant 5-M01-RR-42 to the Clinical Research Unit, University of Michigan Medical Center, Ann Arbor. Mich. Dr. Esler is in receipt of a National Heart Foundation of Australia travel grant. Mr. Ellis is a Cardiovascular Research Trainee in receipt of a grant from the National Institutes of Health.

Address for reprints: Murray Esler, PhD, Hypertension Section, Department of Internal Medicine, University of Michigan Medical Center, Ann Arbor, Mich. 48104.
The relation of renin-angiotensin status to general hemodynamics and to neurogenic vascular resistance was studied in patients with borderline hypertension. Plasma renin activity during standing was referred to a standard renin-urinary sodium nomogram derlved from 18 normal subjects. Among 22 patients with borderline hypertension the renin level was high in $\mathbf{8}$, low in 4 and within normal limits in the remaining 10. In patients with borderline hypertension and high or normal levels of plasma renin activity, the blood pressure elevation was due to increased total peripheral vascular resistance. In contrast, in patients with low renin borderline hypertension, total peripheral resistance was not significantly elevated; the blood pressure elevation reflected a cardiac index 12 percent higher than that in normal subjects.

The neurogenic contribution to total peripheral vascular resistance was assessed by studying the effects of alpha adrenergic blockade with phentolamine, after prior autonomic blockade of the heart with atropine $(0.04 \mathrm{mg} / \mathrm{kg}$ body weight) and propranolol $(0.2 \mathrm{mg} / \mathrm{kg})$. Phentolamine $(15 \mathrm{mg})$ produced an immediate reduction in total peripheral resistance of $12.0 \pm 6.7$ percent in patients with high renin borderline hypertension $(P<0.01$ ) but no change in normal subjects or those with borderline hypertension and normal or low renin levels. Normalization of the blood pressure followed "total" autonomic blockade with atropine, propranolol or phentolamine only in patients with high renin borderline hypertension.

It is concluded from these preliminary data that in high renin borderline hypertension the blood pressure elevation is sustained by neurogenic mechanisms. The elevated renin level in these patients is probably an expression of increased sympathetic nervous activity. Although the elevated plasma renin level may possibly be contributing to the generation of higher sympathetic tone, our data do not support a direct role of circulating angiotensin in the maintenance of the elevated vascular resistance.

Much attention has been focused on the possible role of the reninangiotensin system in the development of human hypertension. In essential hypertension this research appears to be giving new insights into pathogenesis. One finding of interest is the presence of elevated plasma renin levels in a proportion of patients with essential hypertension. ${ }^{1,2}$ The underlying mechanism is unclear, but because of the known role of the sympathetic nervous system in stimulating renin release, ${ }^{3}$ it has been suggested that in essential hypertension with elevated renin levels sympathetic nervous system activity may be in creased. ${ }^{4}$

The renin-angiotension system has been less studied in borderline hypertension, but the presence of high plasma renin activity in a proportion of patients with borderline hypertension has also been described. $^{4-6}$ Since subjects with borderline blood pressure elevation 
appear to be predisposed to the development of established essential hypertension in later life, ${ }^{7}$ it seems appropriate to study such patients in an effort to determine possible initiating factors in the pathogenesis of essential hypertension. This point would appear to apply particularly to any possible interaction between the sympathetic nervous system and the renin-angiotensin system, since the function of both systems seems to be influenced by the duration and severity of the hypertension. ${ }^{4,8-11}$ Changes might be expected to develop with evolution of the hypertensive disease, perhaps obscuring functionally significant interrelations present earlier in the course of development of the hypertension. The relation of renin status in borderline hypertension to some pharmacologic indexes of sympathetic nervous system activity is therefore the subject of this report.

\section{Methods}

\section{Subjects}

Eighteen paid volunteers who had three consecutive normotensive blood pressure readings were compared with 22 patients with borderline hypertension. All subjects were men aged 18 to 35 years. The patients met our definition of borderline hypertension in having, in a minimum of three pressure measurements in the last year, at least one casual diastolic blood pressure reading in excess of $90 \mathrm{~mm} \mathrm{Hg}$, and at least one reading below $90 .{ }^{7}$ Every patient underwent a thorough clinical examination, and none had evidence of secondary hypertension. The examination placed special emphasis on a search for renal disease, pheochromocytoma, hyperthyroidism or a history of renal trauma. During the physical examination, care was taken to exclude diminished or delayed femoral pulses, abdominal bruits, goiter or exophthalmos. All patients had a normal funduscopic examination. Chemical analysis and microscopic study of the urine and serum creatinine and potassium concentrations were normal in all patients. An informed consent form, in which the details of the procedure were outlined, was signed by all subjects. Safety aspects of the procedure were reviewed and approved by this institution's Committee for Use of Human Subjects for Experimental Purposes.

\section{Experimental Procedure}

Stage 1: The study was performed in two stages. In all subjects, a 24 hour sample of urine was collected on an inpatient basis in a metabolic ward for determination of 24 hour urinary sodium excretion. Subjects adhered to their usual diet during this collection period. Urinary sodium concentration was determined by flame photometry. Blood was drawn after 1 hour of standing for estimation of plasma renin activity. Venepuncture was performed at approximately the same time of day in each subject (8 to $9 \mathrm{AM}$ ), and the blood was collected into a chilled tube packed in ice, with ethylenediaminetetraacetic acid (EDTA) as anticoagulant, centrifuged within 1 hour, and the plasma separated, frozen and stored at $-20^{\circ} \mathrm{C}$ before estimation of plasma renin activity. Plasma renin activity was determined by radioimmunoassay of angiotensin I according to the method of Haber et al. ${ }^{12}$

Stage 2: Immediately after the renin collection the 22 patients with borderline hypertension and 14 subjects with normal blood pressure were entered into the second phase of the investigation, in which general hemodynamic mea- surements were made at rest and after autonomic blockade.

The measurement of hemodynamic variables was by methods previously described. ${ }^{13}$ Cardiac output was measured by the dye-dilution technique (using indocyanine green dye), blood pressure measured intraarterially and heart rate determined from simultaneous electrocardiographic tracings. Arterial blood was withdrawn from the brachial artery. A Swan-Ganz flow-directed catheter ${ }^{14}$ was introduced percutaneously into an antecubital vein and advanced, with concurrent monitoring of venous pressure and the electrocardiogram, into the right atrium for delivery of dye for the determination of cardiac output. For monitoring of pressures, the arterial and right atrial catheters were connected through Statham P23 DB strain gauges to a Hewlett-Packard 4578A polygraph. Cardiac output curves were inscribed with a Gilford densitometer. Plasma volume was measured by Evans blue dye. Optical density in samples taken 10, 15 and 20 minutes after the injection of dye was extrapolated to zero time.

Autonomic blockade: Resting measurements were made in all subjects 10 minutes after the catheters were placed. Then intravenous injections of atropine sulfate $(0.04 \mathrm{mg} / \mathrm{kg}$ body weight) and propranolol $(0.2 \mathrm{mg} / \mathrm{kg})$ were given in sequence, each agent being administered over 5 minutes. Hemodynamic measurements were repeated 7 minutes after the administration of each compound. This regimen effectively blocks physiologic autonomic nervous influence on the heart. ${ }^{15}$ Finally the alpha adrenergic blocking drug phentolamine, in a total dose of $15 \mathrm{mg}$, was injected intravenously over 10 minutes, and hemodynamic measurements were repeated 2 minutes later.

To test for the completeness of alpha adrenergic blockade produced by phentolamine, two techniques were used. In one, the pressor response to the rapid intravenous injection of norepinephrine was compared before and after the administration of phentolamine. Sufficient norepinephrine (2 or $3 \mu \mathrm{g}$ ) was administered to produce an increase in mean blood pressure of 20 to $30 \mathrm{~mm} \mathrm{Hg}$ in each subject before administration of phentolamine, and this dose was repeated after administration of phentolamine. In the second, the phase IV diastolic blood pressure overshoot with the Valsalva maneuver ${ }^{16}$ (pressure maintained at $30 \mathrm{~mm}$ $\mathrm{Hg}$ for 15 seconds) was compared before and after administration of phentolamine. In both instances any neurogenic cardiac contribution to the observed response was excluded by the prior administration of blocking doses of atropine and propranolol, so that the modification of both types of response by phentolamine gave an indication of the degree of alpha adrenergic blockade.

\section{Results}

Hemodynamics: The general characteristics of the subjects are shown in Table I. The two groups were well matched for age, but the patients with borderline hypertension had a significantly higher ponderal index (weight/height ${ }^{2}$ ) (Table I). Mean cardiac index and heart rate were similar in patients with borderline hypertension and subjects with normal blood pressure. This finding is at a variance with reports from this laboratory and elsewhere ${ }^{7,17}$ of elevation of the cardiac output in borderline hypertension. Since the cardiac output has previously been found to be elevated in only approximately 30 percent of patients with borderline hypertension, ${ }^{7}$ ours may be a random finding related to sample size. The higher blood pres- 
General Characteristics and Hemodynamics at Rest in Normal Subjects and Patients with Borderline Hypertension (mean \pm standard deviation)

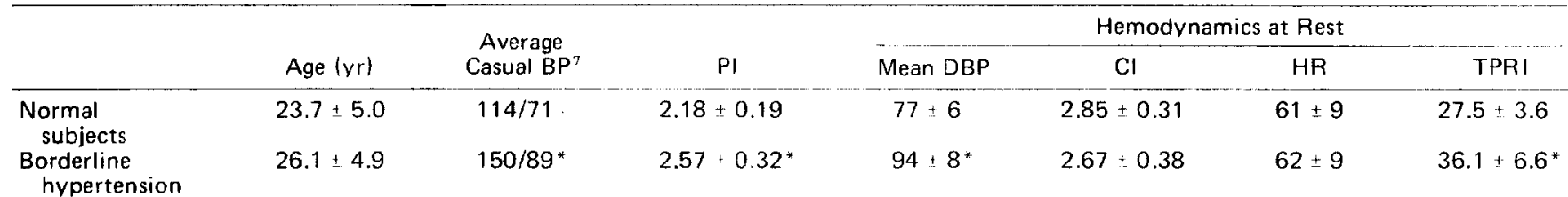

* Significance of difference between the two groups $P<0.01$ (Student's $t$ test).

$\mathbf{B P}=$ blood pressure $(\mathrm{mm} \mathrm{Ha}): \mathrm{Cl}=$ cardiac index $\left(\right.$ liters $/ \mathrm{min}$ per $\left.\mathrm{m}^{2}\right) ; \mathrm{DBP}=$ diastolic blood pressure $+1 / 3$ pulse pressure; HR $=$ heart rate (beats $/ \mathrm{min}) ; \mathrm{PI}=$ ponderal index $\left(\right.$ weight $/$ height $\left.{ }^{2}, \mathrm{~g} / \mathrm{cm}^{2}\right) ; \mathrm{TPRI}=$ total peripheral resistance index $\left(\mathrm{mm} \mathrm{Hg} / \mathrm{liter}\right.$ per $\mathrm{min}$ per $\left.\mathrm{m}^{2}\right)$.

sure in the group of hypertensive patients in this study was, overall, a result of a higher total peripheral vascular resistance (Table I).

Plasma renin activity: The renin status of the patients with borderline hypertension is shown in Fig ure 1. Plasma renin activity was low in 4 , normal in 10 and elevated in 8 of the 22 patients. The mean value was $3.05 \pm 2.35 \mathrm{ng} / \mathrm{ml}$ per hour (mean \pm stan dard deviation) compared with $2.31 \pm 0.89 \mathrm{ng} / \mathrm{ml}$ per hour in subjects with normal blood pressure (difference not significant). Mean 24 hour urinary sodium excretion was similar in hypertensive and normal subjects $(195 \pm 73 \mathrm{mEq}$ and $186 \pm 72 \mathrm{mEq}$, respectively).

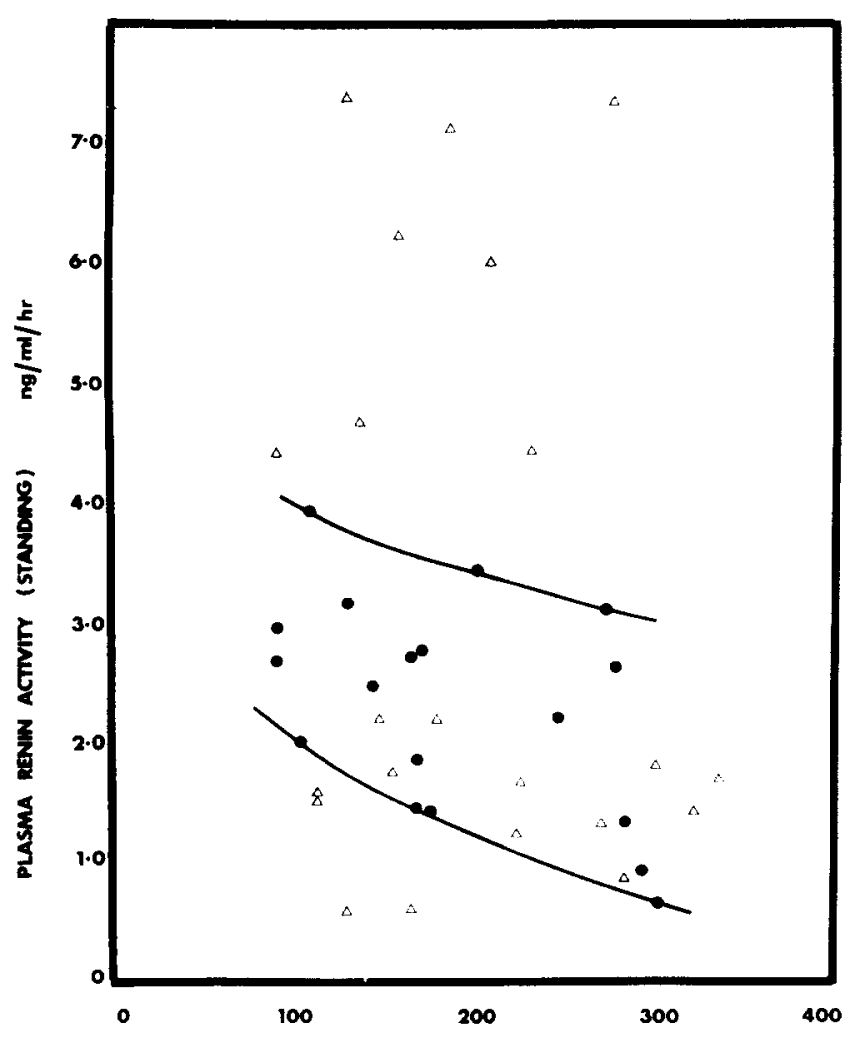

URINARY SODIUM EXCRETION per 24 hours

FIGURE 1. Relation of plasma renin activity to urinary sodium excretion in patients with borderline hypertension (trlangles) and subjects with normal blood pressure (circles). Data from all normal subjects lie within the area bounded by the freely drawn curved lines.
Correlation of hemodynamics and plasma renin status: Among the patients with borderline hypertension, the hemodynamic findings at rest bore a relation to renin status. Mean cardiac index was normal in those with high renin borderline hypertension and reduced in patients with normal renin levels: In both groups the higher blood pressure was due to an elevated total peripheral vascular resistance (Table II). In contrast, calculated peripheral resistance was not significantly elevated in those with low renin borderline hypertension. The number of subjects in this group was small (four only) so the results must be considered preliminary. In patients with low renin borderline hypertension the elevated blood pressure was maintained by (1) a modestly elevated cardiac index (12 percent higher than in normal subjects: $3.19 \pm 0.23$ liters $/ \mathrm{min}$ per $\mathrm{m}^{2}$ compared with $2.85 \pm 0.31$ liters $/ \mathrm{min}$ per $\mathrm{m}^{2} ; 0.05<P<0.1$ ), and (2) a peripheral resistance that had not decreased to accommodate the increased cardiac output $^{18}$ (Table II). The higher cardiac index reflected solely an elevated stroke volume, the heart rate being similar to that in normal subjects and in the other renin subgroups with borderline hypertension (Table II). The increased stroke volume in the group with low renin borderline hypertension was not a consequence of volume loading of the left ventricle from expansion of plasma volume; plasma volume and total blood volume were similar in normal subjects and patients with borderline hypertension and sup. pressed plasma renin activity (Table II). Plasma volume was reduced in the hypertensive patients with elevated renin levels. A reduction in plasma volume in patients with borderline hypertension, uncategorized in relation to renin status, has previously been reported. ${ }^{19}$

Hemodynamic responses to autonomic blockade: After administration of atropine plus propranolol, mean blood pressure increased significantly in patients with borderline hypertension and in normal subjects (Fig. 2). The increase in blood pressure resulted from an elevation of the cardiac index after cardiac autonomic blockade $(0.84 \pm 0.46 \mathrm{liter} / \mathrm{min}$ per $\mathrm{m}^{2}$ in normal subjects and $0.26 \pm 0.12 \mathrm{liter} / \mathrm{min}$ per $\mathrm{m}^{2}$ in patients with borderline hypertension). The larger increase in cardiac output in normal subjects is in agreement with an earlier report from this laboratory of diminished autonomic restraint of 
TABLE ||

Hemodynamic and Volume Correlates of Renin Status (means \pm 1 standard deviation)

\begin{tabular}{|c|c|c|c|c|c|c|c|}
\hline & Mean BP & $\mathrm{Cl}$ & TPRI & $\mathrm{HR}$ & SVI & PV & BV \\
\hline $\begin{array}{l}\text { Normal } \\
\text { subjects } \\
\text { Borderline } \\
\text { hypertension }\end{array}$ & $77 \pm 6.4$ & $2.85 \pm 0.31$ & $27.5 \pm 3.6$ & $61 \pm 9$ & $47.1 \pm 5.3$ & $160 \% \pm 240$ & $2740 \pm 325$ \\
\hline $\begin{array}{l}\text { High renin } \\
\text { Normal renin } \\
\text { Low renin }\end{array}$ & $\begin{array}{l}93.8 \pm 5.5^{\dagger} \\
95.2 \pm 10.9^{\dagger} \\
93.5 \pm 5.8^{\dagger}\end{array}$ & $\begin{array}{l}2.63 \pm 0.26 \\
2.49 \pm 0.32^{*} \\
3.19 \pm 0.23\end{array}$ & $\begin{array}{l}35.9 \pm 4.1^{\dagger} \\
38.9 \pm 7.5^{\dagger} \\
29.3 \pm 3.1\end{array}$ & $\begin{array}{l}64 \pm 7 \\
62 \pm 11 \\
58 \pm 6\end{array}$ & $\begin{array}{l}41.3 \pm 5.8^{*} \\
41.4 \pm 8.9^{*} \\
55.5 \pm 3.3^{*}\end{array}$ & $\begin{array}{l}1375 \pm 146^{*} \\
1461 \pm 138 \\
1589 \pm 58\end{array}$ & $\begin{array}{l}2482 \pm 210^{*} \\
2699 \pm 136 \\
2701 \pm 153\end{array}$ \\
\hline
\end{tabular}

Significance of differences between the values for each renin subgroup and the normal subjects $P<0.05\left(^{*}\right)$ or $P<0.01$ ( $t$ ) by Student's $t$ test. $\mathrm{BP}=$ blood pressure $(\mathrm{mm} \mathrm{Hg}) ; \mathrm{BV}=$ blood volume $\left(\mathrm{cc} / \mathrm{m}^{2}\right) ; \mathrm{Cl}=$ cardiac index $\left(\right.$ liters $/ \mathrm{min}$ per $\left.\mathrm{m}^{2}\right) ; \mathrm{HR}=\mathrm{heart} \mathrm{rate}(\mathrm{beats} / \mathrm{min}) ; \mathrm{PV}=\mathrm{plasma}$ volume $\left(\mathrm{cc} / \mathrm{m}^{2}\right): \mathrm{SVI}=$ stroke volume index $\left(\mathrm{cc} / \mathrm{m}^{2}\right) ; \mathrm{TPRI}=$ total peripheral resistance index $\left(\mathrm{mm} \mathrm{Hg} / \mathrm{liter} / \mathrm{per} \mathrm{min}\right.$ per $\left.\mathrm{m}^{2}\right)$.

cardiac output in borderline hypertension. ${ }^{20}$ Among the patients with borderline hypertension, the rise in blood pressure after administration of atropine and propranolol was most pronounced in those with normal renin levels $(10.4 \pm 6.1 \mathrm{~mm} \mathrm{Hg}, P<0.01)$, somewhat less in those with low renin levels $(5.5 \pm 3.2 \mathrm{~mm}$ $\mathrm{Hg}, P<0.05$ ), and absent in those with high renin levels. Total peripheral vascular resistance decreased after atropine plus propranolol in normal subjects (from $27.5 \pm 3.5 \mathrm{~mm} \mathrm{Hg} /$ liters per min per $\mathrm{m}^{2}$ to 23.7 $\pm 3.0 \mathrm{~mm} \mathrm{Hg} /$ liters per min per $\mathrm{m}^{2}, P<0.01$, paired $t$ test), but was unchanged in those with borderline hypertension.

After the addition of phentolamine, to produce "total autonomic blockade," there was a similar and significant reduction in mean blood pressure in both groups $(11.8 \pm 7.7 \mathrm{~mm} \mathrm{Hg}$ in patients with borderline hypertension and $10.7 \pm 7.0 \mathrm{~mm} \mathrm{Hg}$ in subjects with normal blood pressure, $P<0.01$ ). The basis of the reduction in blood pressure after administration of
FIGURE 2. General hemodynamics at rest, after atropine plus propranolol, and after "total" autonomic blockade in patients with borderline hypertension (triangles) and normal subjects (circles). Mean values \pm 1 standard deviation are shown. The significance levels of the changes from resting values with atropine plus propranolol ("cardiac autonomic blockade") and the subsequent changes with phentolamine are indicated for both groups of subjects (" probability $<0.05$, * " probability <0.01; paired $t$ test).
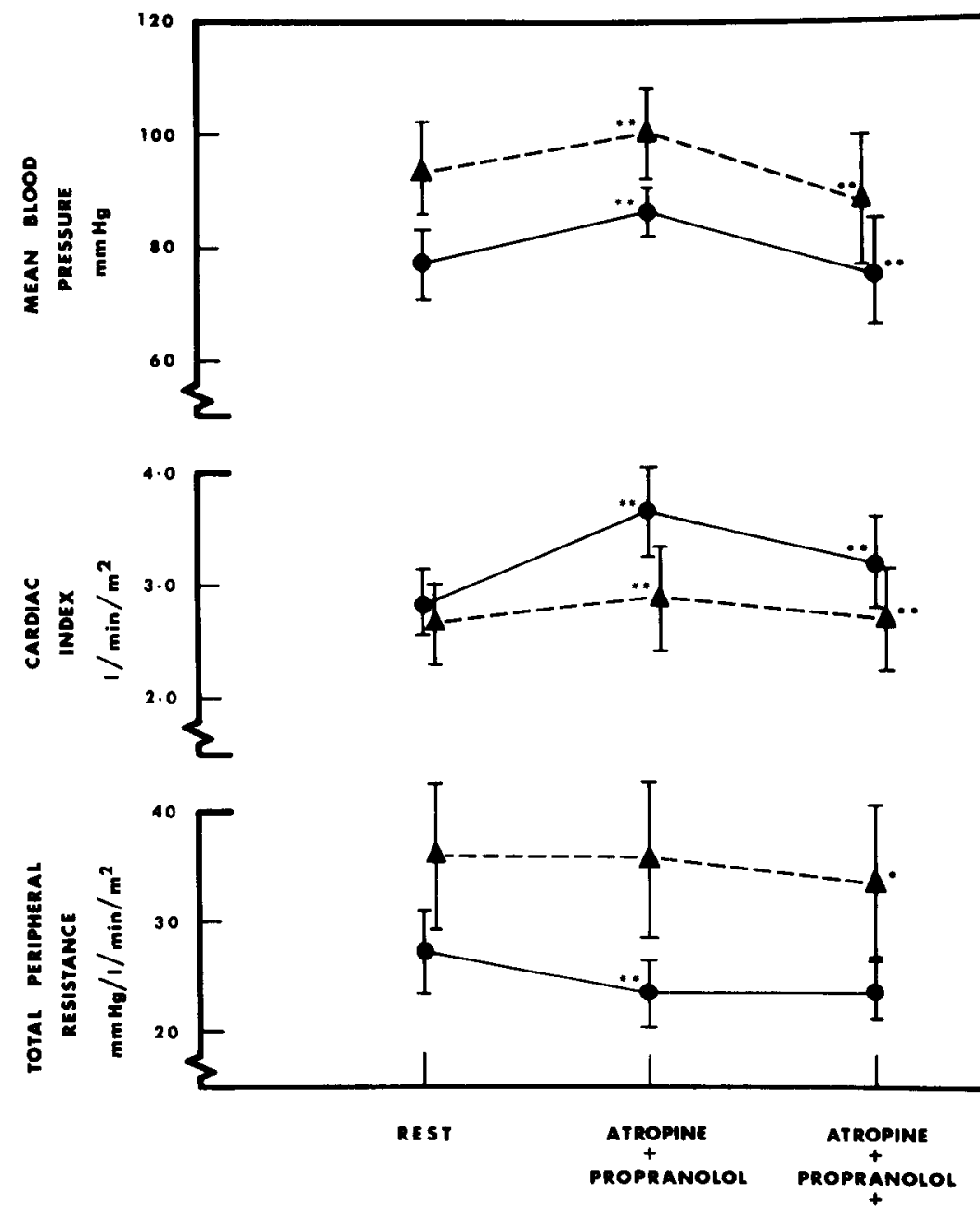

Normal BP A Borderline Hypertension 


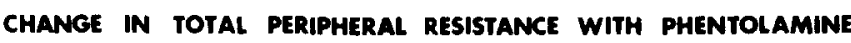

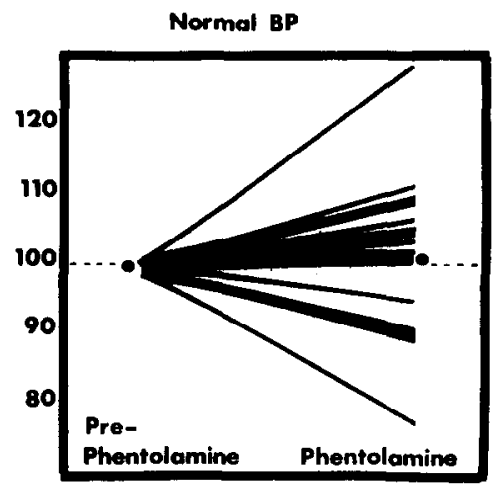

Normal Renin Borderline Hypertension

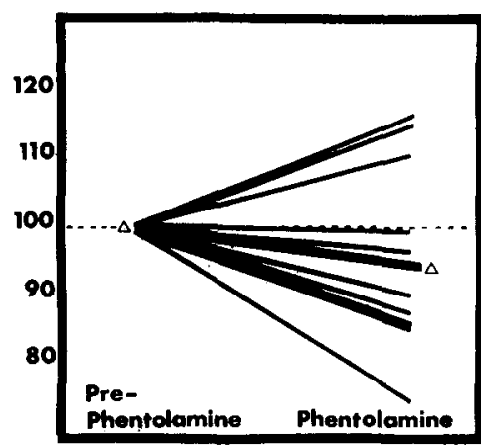

High Renin Borderline Mypertension

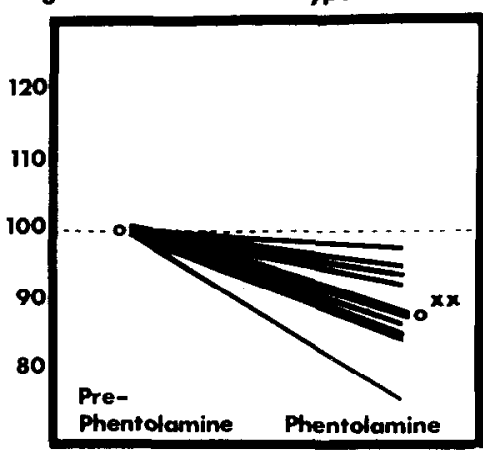

Low Renin Borderline Hypertension

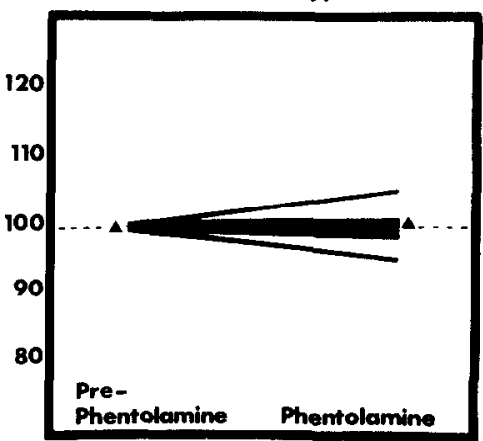

$x \times p<0.01$

FIGURE 3. The effect of phentolamine on total peripheral resistance in borderline hypertension expressed in relation to renin status. Total peripheral resistance before administration of phentolamine (after cardiac autonomic blockade with atropine plus propranolol) is recorded as 100 percent. Individual responses to alpha adrenergic blockade with phentolamine are shown, and mean responses are indicated by the heavy line and symbol. There was a significant reduction in peripheral resistance in the patients with high renin borderline hypertension only ( $x x$ probability $<0.01$, paired $t$ test). phentolamine was a reduction in cardiac index in both groups, particularly in the normal subjects $(0.47$ \pm 0.24 liter $/ \mathrm{min}$ per $\mathrm{m}^{2}$ compared with $0.18 \pm 0.26$ liter $/ \mathrm{min}$ per $\mathrm{m}^{2}$ ) and a decrease in total peripheral resistance only in the patients with borderline hypertension. Although the latter group did not uniformly have a reduction in peripheral resistance with phentolamine, the mean overall response of $-6.3 \pm 12.6$ percent was significant at the 5 percent level.

Renin status and responses to phentolamine: The responses to phentolamine of blood pressure and peripheral resistance appeared to be related to renin status among the patients with borderline hypertension. Phentolamine produced a reduction of $14 \pm 5$ $\mathrm{mm} \mathrm{Hg}$ in mean blood pressure in the group with high renin borderline hypertension $(P<0.01$, paired $t$ test) and a reduction in peripheral vascular resistance of $12 \pm 7$ percent $(P<0.01)$. In the group with low renin borderline hypertension, the reduction in mean blood pressure with phentolamine was $6 \pm 4$ $\mathrm{mm} \mathrm{Hg}$ (not statistically significant), whereas peripheral resistance was unchanged (Fig. 3). In patients with borderline hypertension with a normal renin level, in whom there had been a significant increase in cardiac output and blood pressure after cardiac autonomic blockade, phentolamine reduced blood pressure by $13 \pm 10 \mathrm{~mm} \mathrm{Hg}(P<0.01)$, largely because of a reduction in cardiac output since peripheral resistance did not change significantly (Fig. 3). After total autonomic blockade, the blood pressure was normalized in patients with high renin borderline hypertension, but it remained elevated in those with low and normal renin borderline hypertension (Fig. 4).

Phentolamine and alpha adrenergic vascular responses: As an index of the completeness of alpha adrenergic blockade, pressor responses to injected

\section{TABLE III}

Completeness of Alpha Adrenergic Blockade with Phentolamine (mean + 1 standard deviation)*

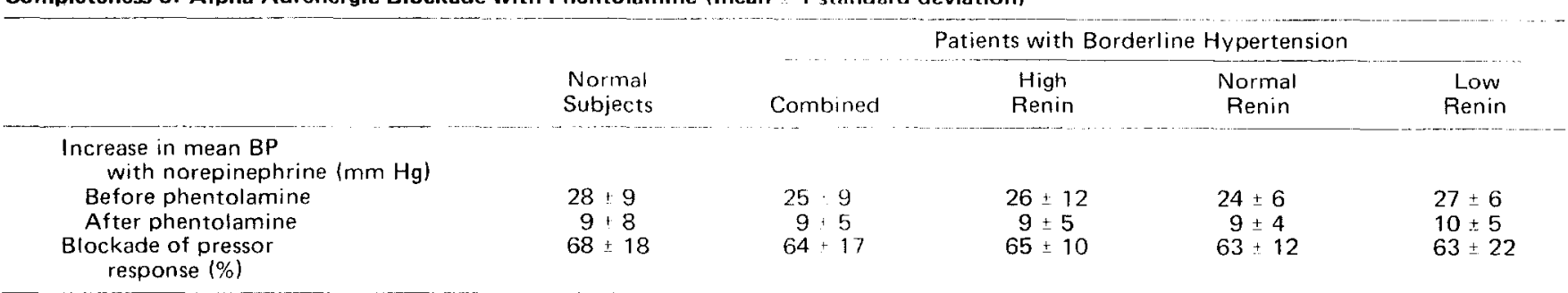

The blood pressure response to 2 or $3 \mu \mathrm{g}$ norepinephrine was measured betore and after administration of norepinephrine, and the percent blockade of the response calculated. 
norepinephrine before and after the administration of phentolamine were compared. A comparable degree of alpha adrenergic blockade by phentolamine was demonstrated in patients with borderline hypertension and normal subjects, and among the three renin subgroups of patients with borderline hypertension (Table III). The effect of phentolamine on the post-straining phase of diastolic blood pressure overshoot with the Valsalva maneuver was studied in cight subjects with borderline hypertension. This study was performed to enable a qualitative judgment as to whether phentolamine interfered with alpha adrenergic vascular responses mediated by the sympathetic nervous system. The effect of phentolamine on the response was studied after cardiac autonomic blockade with atropine and propranolol. Both the diastolic overshoot $(23 \pm 5 \mathrm{~mm} \mathrm{Hg}$ before administration of phentolamine compared with $9 \pm$ $11 \mathrm{~mm} \mathrm{Hg}$ after administration) and the Valsalva index $^{* 16}(0.65 \pm 0.10$ and $0.34 \pm 0.25$, respectively, before and after administration of phentolamine) were significantly reduced by the drug $(P<0.05$, paired $t$ test).

\section{Discussion}

Plasma renin subgroups in borderline hypertension: The distribution of patients in the different renin subcategories in our study was somewhat similar to that reported in essential hypertension, but high renin values were more common (found in approximately 35 percent of our subjects with borderline hypertension) than previously described in established essential hypertension. ${ }^{1}$ There have been several earlier reports of high plasma renin activity in a proportion of patients with borderline hypertension. ${ }^{5,6}$ Although suppressed renin levels have previously been noted in some patients with borderline hypertension, ${ }^{4}$ low renin borderline hypertension has not been the subject of systematic study.

Among the patients with borderline hypertension, the different renin subgroups exhibited certain hemodynamic dissimilarities. In those with high or normal renin levels, the blood pressure elevation was due solely to elevated peripheral vascular resistance. In contrast, in patients with low plasma renin activity, total peripheral vascular resistance was not increased. The higher blood pressure was sustained by an above normal cardiac output and peripheral vascular resistance which, although within normal limits, was elevated for the level of cardiac output. ${ }^{18}$

Peripheral vascular resistance in borderline hypertension: When the neurogenic contribution to total peripheral vascular resistance and to blood pressure was studied, differences between the normal subjects and the patients with borderline hypertension emerged. Alpha adrenergic blockade with phentolamine, after cardiac autonomic blockade with atropine plus propranolol, produced no change in total peripheral vascular resistance in normal subjects. In contrast, there was a significant reduction in resis-

( $)$ Valsalva index $=$ diastolic overshoot percent/pulse pressure reduction with straining percent. ${ }^{16}$

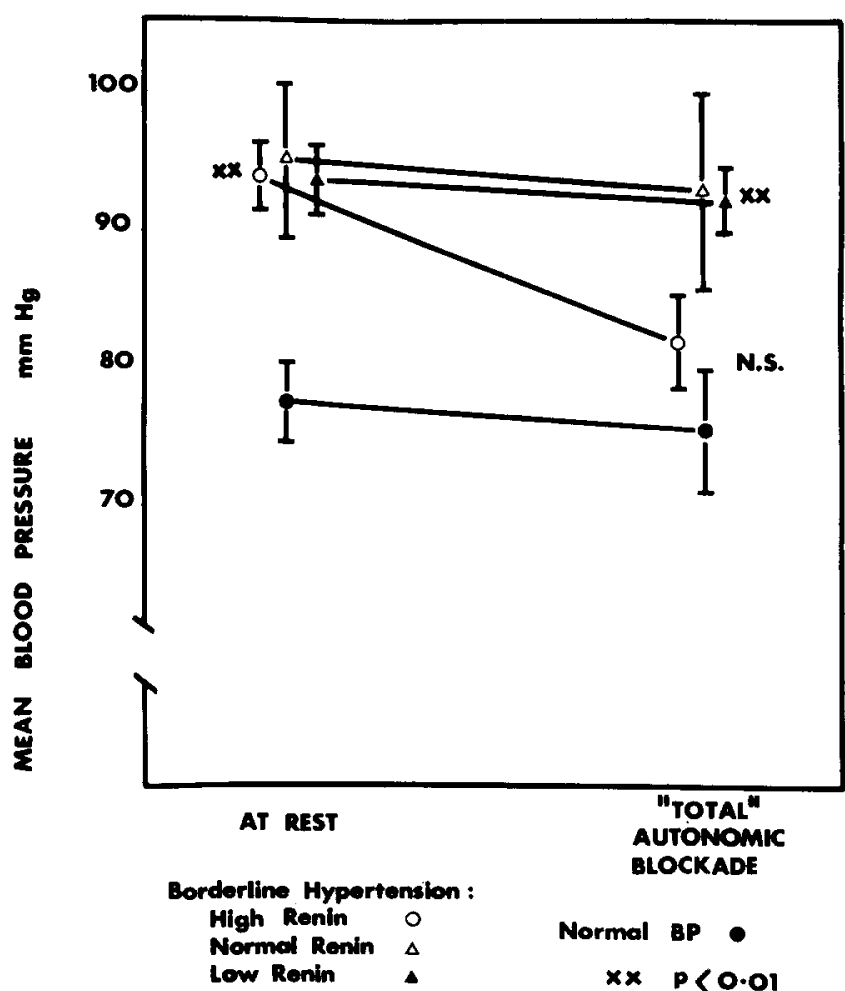

FIGURE 4. The effect of "total' autonomic blockade on mean blood pressure (diastolic blood pressure $+1 / 3$ pulse pressure) in normal subjects and renin subgroups of patients with borderline hypertension. Means \pm 1 standard deviation are shown. The significance level refers to the difference in mean blood pressure between the normal subjects and each group with borderline hypertension (Student's $t$ test). Atter total autonomic blockade mean blood pressure in normal subjects and patients with high renin borderline hypertension was not significantly different $(82.0 \pm 6.6 \mathrm{~mm} \mathrm{Hg}$ compared with $75.7 \pm$ $9.2 \mathrm{~mm} \mathrm{Hg}$ ).

tance in the group with borderline hypertension although the response was not uniform. In hypertensive patients with normal or low renin levels, total peripheral vascular resistance was not significantly reduced with phentolamine; a significant drop in resistance was noted only in the high renin group. This finding suggests that there is a greater neurogenic contribution to the maintenance of vascular resistance in the group with high renin borderline hypertension than in the other groups studied.

Vascular responsiveness in borderline hypertension: It might be asked whether there is increased sympathetic stimulation of arterioles in high renin borderline hypertension, or rather increased responsiveness of the resistance vessels to a normal level of stimulation, perhaps on the basis of secondary morphologic changes in the arteriolar wall. ${ }^{21}$ The latter interpretation is unlikely, although not excluded. If a secondary increase in vascular responsiveness were the basis for increased neurogenic maintenance of vascular resistance, the patients in the borderline hypertensive group with the highest levels of blood pressure and total peripheral vascular resistance should have been most responsive to phentolamine. This was not the case. Overall among patients with borderline hypertension there was no correlation between total peripheral vascular resistance and the response to phentolamine; in fact, patients with high 
renin borderline hypertension had marginally lower mean peripheral vascular resistance than those with normal renin levels.

Mechanism of reduction of blood pressure with phentolamine: It was a puzzling finding in this study that with phentolamine, cardiac output was reduced more in normal subjects and in patients with normal renin borderline hypertension than in those with high renin borderline hypertension. The basis of the decrease in cardiac output was a reduction in stroke volume, so the response presumably resulted from venodilatation secondary to alpha adrenergic blockade. Thus, with phentolamine, the mechanism of the reduction in blood pressure appeared to be venodilatation in normal subjects and the group with normal renin borderline hypertension, in contrast to arteriolar dilatation in the group with high renin borderline hypertension. This finding appears to imply a differ ent distribution of sympathetic nervous system tone in the different groups, more to arterioles in patients with high renin horderline hypertension and more to veins in those with borderline hypertension and nor mal renin levels. However, this may not be the case. Since plasma volume at rest was diminished only in the group with high renin borderline hypertension, any excessive reduction in cardiac output with phentolamine would have been expected to occur in this group, in which, in view of the smaller plasma volume, increased adrenergic stimulation of veins and postcapillary venules might be anticipated. ${ }^{22}$

An explanation for these apparently anomalous findings may perhaps be found in the stimulus-re sponse characteristics of capacitance vessels, as described by Mellander..$^{23}$ At usual rates of sympathetic nerve discharge (1 to $2 / \mathrm{sec}^{24}$ ) the stimulus-response curve for veins is much steeper than that of arterioles. But maximal venoconstriction occurs at a firing rate of only 3 to $4 / \mathrm{sec}^{23}$ With a competitive antagonist such as phentolamine, the rate of sympathetic nerve firing would be critical in determining the magnitude of the response. A stimulated vein, situated on the plateau of the stimulus-response curve, would respond to, say, 50 percent blockade with little change in caliber, whereas a vein subjected to a lower rate of sympathetic stimulation, and situated on the steep portion of the curve, would exhibit a greater increase in diameter with blockade. In view of these complexities, the possibility that increased adrenergic venous tone accompanies increased arteriolar tone in high renin borderline hypertension must remain an open question.

Phentolamine and alpha adrenergic blockade: Some comment must be made on the pharmacologic properties of phentolamine, and to what extent the change in peripheral vascular resistance produced by this drug reflects the effect of alpha adrenergic blockade. The reduction in vascular resistance produced by the intravenous administration of phentolamine in man is very rapid. This led Taylor et al. ${ }^{25}$ to conclude that the predominant mechanism was a direct vasodilatation. That phentolamine acts as a direct vasodilator has never been demonstrated, and studies on reserpinized dogs suggest an absence of such an action. ${ }^{26}$ Recently, Zahir and Gould ${ }^{27}$ demonstrated a beta adrenergic component in the vasodilatation and decrease in blood pressure with phentolamine. This component is abolished by propranolol ${ }^{27}$ and was eliminated by the design of our study, in which phentolamine was given after prior administration of propranolol. Phentolamine produced a diminution in the diastolic blood pressure overshoot with the Valsalva maneuver, which suggests that phentolamine blocks alpha adrenergic vasomotor effects mediated by sympathetic nerves. ${ }^{16}$ The finding is in conflict with the concept that phentolamine blocks circulating catecholamines only, with little or no inhibition of norepinephrine released from sympathetic nerves. It seems reasonable to conclude that the resistance response observed in this study with phentolamine was a consequence of alpha adrenergic blockade.

Sympathetic nervous system activity in borderline hypertension: Normalization of the blood pressure was produced by "total" autonomic blockade in the patients with high renin borderline hypertension. This finding suggests a dominant role for neurogenic factors in the maintenance of the elevated blood pressure in these patients. In contrast, in the group with borderline hypertension and normal renin levels, the blood pressure remained elevated after autonomic blockade. Whether such a lack of response indicates that patients with normal renin borderline hypertension have morphologic arteriolar changes causing increased resistance to flow ${ }^{21}$ requires further investigation. In established essential hypertension, a significant nonneurogenic component has been implicated in the pathogenesis of the existing elevated total peripheral vascular resistance. ${ }^{28}$

The blood pressure elevation in the group with low renin borderline hypertension also proved resistant to autonomic blockade. There is some evidence of suppressed sympathetic nervous system function in low renin essential hypertension, ${ }^{4}$ in which the blood pressure elevation is widely regarded as volume-dependent. ${ }^{29}$ Unresponsiveness, in a therapeutic setting, of low renin essential hypertension to adrenergic blocking drugs has also been noted. ${ }^{30,31}$ However, blood or plasma volume was not elevated in our small group of patients with low renin levels although their cardiac output and stroke volume tended to be high. Thus in these patients the determinants of the enhanced cardiac performance deserve further investigation.

In this study, the patients with borderline hypertension and elevated plasma renin activity showed a significant decrease in peripheral vascular resistance and normalization of the blood pressure after alpha adrenergic blockade. Thus greater blood pressure was sustained by a neurogenic, not an angiotensin-dependent, peripheral vasoconstriction. Since the sympathetic nervous system, by way of the renal sympathetic nerves, plays a key role in the control of renin release, ${ }^{3}$ the finding of increased sympathetic arteriolar tone in patients with borderline hypertension with elevated plasma renin activity suggests that in- 
creased sympathetic nervous system activity may determine the renin status in this group. However, the origin of the increased sympathetic activity in these patients with high renin borderline hypertension is not clear. Further, the question of the primacy of increased sympathetic activity over the plasma renin elevation is not entirely settled. Central and peripheral enhancement of sympathetic nervous system function by angiotensin has been described, ${ }^{32}$ so a possible role of the renin-angiotensin system in the generation of the sympathetic overactivity must still be entertained.

\section{Acknowledgment}

A gift of propranolol by Roger Mazlen, MD, of Ayerst Pharmaceuticals is gratefully acknowledged.

\section{References}

1. Brunner HR, Laragh JH, Baer $L$, ef al: Essential hypertension: renin and aldosterone, heart attack and stroke. $N$ Engl $\mathrm{J} \mathrm{Med}$ 286:441-449, 1972

2. Esler MD, Nestel PJ: Essential hypertension with symptoms of hyperkinetic circulation. Med J Aust 2:253-257, 1973

3. Vander AJ: Effect of catecholamines and the renal nerves on renin secretion in anesthetized dogs. Am J Physiol 209:659662,1965

4. Esler MD, Nestel PJ: Renin and sympathetic nervous system responsiveness to adrenergic stimuli in essential hypertension. Am J Cardiol 32:643-649, 1973

5. Frohilich ED, Kozul VJ, Tarazl RC, ot al: Physlological comparison of labile and essential hypertension. Circ Res 46: Suppl I: $55-69,1970$

6. Kuchel O, Cuche JL, Barbeau A, et al: The relative excess of norepinephrine over dopamine and renin hyper-responsiveness in hyperkinetic circulation: a possibly hereditary disorder (abstr). $\mathrm{J}$ Clin Invest 49:53a-54a, 1970

7. Jullus S, Schork MA: Borderline hypertension-a critical review. J Chronic Dis 23:723-754, 1971

8. Frohlich ED, Tarazl RC, Uirych $\mathbf{M}$, et al: Tilt test for investigating a neural component in hypertension. Its correlation with clinical characteristics. Circulation 36:387-393, 1967

9. Esler MD, Nestel PJ: Sympathetic responsiveness to head-up tilt in essential hypertension. Clin Sci 44:213-226, 1973

10. Esler MD, Nestel PJ: High catecholamine essential hypertension: clinical and physiological characteristics. Aust $\mathrm{N} Z \mathrm{~J} \mathrm{Med}$ 3:117-123, 1973

11. Sambhl MP, Crane MC, Genest J: Essential hypertension: new concepts about mechanisms. Ann Intern Med 79:411-424, 1973

12. Haber E, Koerner T, Page LB, ef al: Application of a radioimmunoassay for angiotensin I to the physiologic measurements of plasma renin activity in normal human subjects. J Clin Endocrinol Metab 29:1349-1355, 1969

13. Ellis CN, Jullus S: Role of central blood volume in hyperkinetic borderline hypertension. Br Heart J 35:450-455, 1973

14. Swan HJ, Ganz W, Forrester J, et al: Catheterization of the heart in man with use of a flow-directed balloon-tipped catheter. N Engl J Med 283:447-451, 1970

15. Jose AD, Taylor RR: Autonomic blockade by propranolol and atropine to study intrinsic myocardial function in man. J Clin Invest 48:2019-2031, 1969

16. Sharpey-Schafer EP: Effects of Valsalva's manoeuvre on the normal and failing circulation. Br Med J 1:693-695, 1955
17. Elch RH, Peters RJ, Cuddy RP, et al: Hemodynamics in labile hypertension. Am Heart J 63: 188-195, 1962

18. Jullus S, Pascual A, Sannerstedt R, et al: Relationship between cardiac output and peripheral resistance in borderline hypertension. Circulation 43:382-390, 1971

19. Jullus S, Pascual A, Relly K, of al: Abnormalities of plasma volume in borderline hypertension. Arch Intern Med 127:116-119, 1971

20. Jullus S, Pascual AV, London R: Role of parasympathetic inhibition in the hyperkinetic type of borderline hypertension. Circulation 44:413-418, 1971

21. Slvertsson R: The hemodynamic importance of structural vascular changes in essential hypertension. Acta Physiol Scand 79: Suppl 343: 1970

22. Davls DL: Effect of sympathetic stimulation on dog paw volume. Am J Physiol 205:989-994, 1963

23. Mellander S: Comparative studies on the adrenergic neuro-hormonal control of resistance and capacitance blood vessels in the cat. Acta Physiol Scand 50: Suppl 176: 1960

24. Lundgren $O$, Lundwall J, Mellander S: Range of sympathetic discharge and reflex vascular adjustments in skeletal muscle during hemorrhagic hypotension. Acta Physiol Scand 62:380390,1964

25. Taylor SH, Sutherland GR, Mackenzle GJ, et al: The circulatory effects of intravenous phentolamine in man. Circulation 31 : 741-747, 1965

26. Hilliard CC, Bagwell EE, Daniell HB: Effects of sympathetic and central nervous alterations on the blood pressure response to phentolamine. J Pharmacol Exp Ther 180:743-747, 1972

27. Zahir M, Gould L: Phentolamine and beta-adrenergic receptors. $\mathrm{J}$ Clin Pharmacol 11:197-203, 1971

28. Korner PI, Shaw J, Uther JB, et al: Autonomic and non-autonomic circulatory components in essential hypertension in man Circulation 48:107-117, 1973

29. Laragh JH: Vasoconstrictor-volume analysis for understanding and treating hypertension: the use of renin and aldosterone profiles. Am J Med 55:261-274, 1973

30. Bühler FR, Laragh JH, Baer L, ef al: Propranolol inhibition of renin secretion. N Engl J Med 287: 1209-1214, 1972

31. Weldemann P, Hirsch D, Okun R, et al: Renin-blood pressure interrelations during sympathetic inhibition with methyldopa (abstr). Clin Res 21:458, 1973

32. Ferrarlo CM, Glldenberg PL, McCubbin JW: Cardiovascular effects of angiotensin mediated by the central nervous system. Circ Res 30:257-262, 1972 